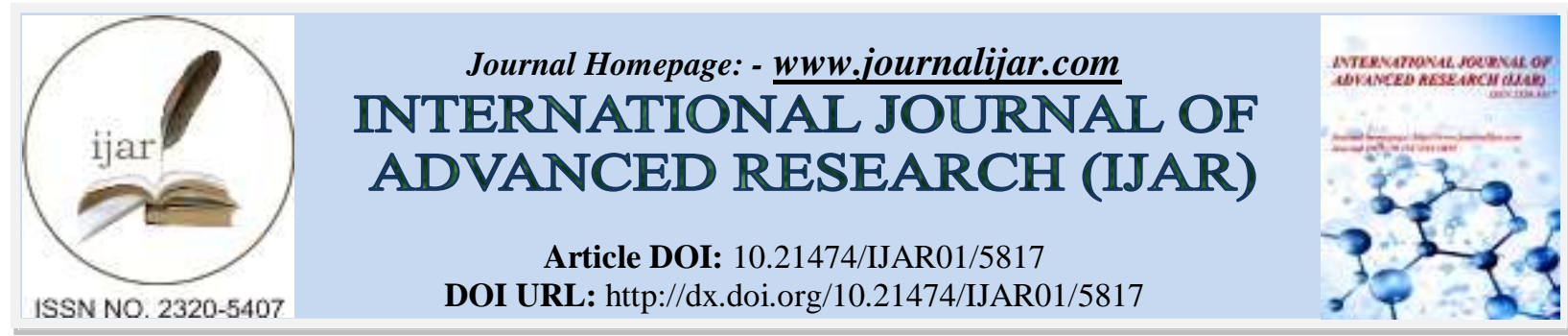

RESEARCH ARTICLE

\title{
A NEW APPROACH TO FOOT PROBLEMS CAUSED BY PRESSURE AT DIABETIC FOOT PATIENTS: TOTAL ORTHOPEDIC FOOTWEAR.
}

\section{Dr. Goksen SURUCU.}

\section{Manuscript Info}

(.........................

Manuscript History

Received: 09 September 2017

Final Accepted: 11 October 2017

Published: November 2017

Key words:-

Diabetic foot, pressure, orthopedic, footwear.

\section{Abstract}

Background and Objective: Diabetic foot (DF) is a syndrome mainly caused by pressure developed with neuropathic and peripheral artery complication of Diabetes Mellitus (DM) with comorbid infection, and has negative effects on both physical and psychological health of patients. Increasing foot pressure causes some footwear related problems, thus there is some alternative footwear for DF patients. However, recent alternative footwear types only focus on sole, and other pressure points (tarsus, metatarsus, foot surface) are dismissed. In this research, it was aimed to compare pressure and pain levels of soleoriented footwear (full orthopedic) and whole foot-oriented footwear (total orthopedic).

Methods: In the research, a total of 30 patient files (16 females and 14 males) having DF with Type I or II DM were retrospectively subjected to study. Arterial pressures (systolic-diastolic), total foot pressure, foot metatarsus and tarsus pressures at initial, 10th, 60th and 120th minutes were compared with both footwear types with pain levels. Results: According to results, total orthopedic footwear pressure results were lower than full orthopedic footwear for all parameters. At initial point, differences between all pressure parameters found to be statistically insignificant $(p>0,05)$. On the other hand, differences between two footwear types at the 10th minute for right and left foot were statistically significant $(\mathrm{p}<0,05)$. In addition, all foot pressure parameters showed statistically significant differences at 60th and 120th-minute results.

Conclusion: Results of the study shows that total orthopedic footwear significantly reduces feet pressure in DF, and increases foot health quality of DF patients. Moreover, the developed footwear may help to reduce foot related other health problems, especially infectious comorbid diseases.

\section{Introduction:-}

DF syndrome is characterized by pressure developed neuropathic and peripheral artery complication of DM with comorbid infection. It has negative effects on, especially DM Type II patients both physical and psychological life. In addition, DF is responsible for nearly half of all DM related hospitalization (Ahmad, 2016). Prevalence data on DF is very poor and depending on the country, region or study, ranging from 3 to $25 \%$ of DM patients (Besse et al, 
2011). It was also reported that as many as 50\% of elderly patients having Type II DM have a higher risk factor for DF (Boulton, 2015). Extremity ulcer including the foot in DM is reported about 2-10\% of total DM patients (Chand et al, 2012).

The basic physical human functions such as walking, running etc. are mainly related with the biomechanics of foot (Bishop et al, 2017). Since the foot is a fragile body region, its lesions and injuries require long recovery periods (Caravaggi et al, 2016).

Increasing feet pressure causes some footwear related problems, thus there is some alternative footwear for DF patients. However, recent alternative footwear types only focus on sole and plantar foot pressure assessment (Frykberg et al. 1998; Pham et al. 2000; Arts and Bus, 2011). On the other hand, it is also reported that full orthopedic or sole-oriented footwear has not minimized foot related problems developed with DF such as foot ulcer. For this reason, it was aimed to compare pressure and pain levels of sole-oriented footwear (full orthopedic) and whole foot-oriented footwear (total orthopedic footwear that covers foot $(\mathrm{OFCoF})$ ) in the research.

\section{Methods:-}

In the study, a total of 30 patient files (16 females and 14 males) having DF with Type I or II DM, attempted to control during 01.01.2016 to 01.05.2017 were retrospectively subjected to study. Arterial blood pressures (systolicdiastolic), total foot pressure, foot metatarsus and tarsus circumferences at initial, 10th, 60th and 120th minutes were compared with sole-oriented footwear (full orthopedic) and OFCoF (Dia Comfort@) with pain levels. Total foot pressure, foot metatarsus circumference, and tarsus circumference were measured by squeezing with a blood pressure sleeve and measuring the pressure with which the current was generated at medial malleoli level. The circumference of the ankle and the circumference of the metatarsal were made by removing the shoes after the pressure measurements and wearing the shoes again. The patients were mobilized outside these periods. Pain level assessment was done according to the discourse of the patients.

Difficulties in finding patients wearing two footwear types who were followed up for four time periods were an important restriction for a number of patients. In addition, patients who were sick abed, have no opportunity to wear footwear, other comorbid diseases affecting foot pressure were excluded.

In statistical analysis, SPSS 17.0 for Windows was used. Categorical parameters (gender) were described with frequency analysis. Baseline characteristics in scale form and pressure parameters with pain scale results were described with mean and standard deviation. Kolmogorov-Smirnov (KS) test was used to control normality of scale parameters. Since KS results showed a non-normal distribution, nonparametric tests were used. Mann Whitney-U test was used to analyze differences between footwear groups. All analysis was performed at $95 \%$ confidence interval with a 0,05 alpha level.

\section{Results:-}

Baseline characteristics of patients were given in the Table 1.

Table 1:- Baseline characteristics of patients

\begin{tabular}{|l|l|}
\hline Parameters & Values \\
\hline Gender & \\
\hline Female, n (\%) & $16(53,30)$ \\
\hline Male, n (\%) & $14(46,70)$ \\
\hline Age, years, Mean \pm SD (min-max) & $48,67 \pm 11,67(22-72)$ \\
\hline Weight, kg, Mean \pm SD (min-max) & $78,90 \pm 12,14(55-110)$ \\
\hline Height, cm, Mean \pm SD (min-max) & $167,80 \pm 8,74(150-182)$ \\
\hline BMI, Mean \pm SD (min-max) & $28,00 \pm 3,48(21,71-35,51)$ \\
\hline Foot number, cm, Mean \pm SD (min-max) & $40,37 \pm 2,78(36-45)$ \\
\hline Walking length, km, Mean \pm SD (min-max) & $4,67 \pm 2,12(2-10)$ \\
\hline
\end{tabular}

A total of 30 patients, including 16 female and 14 male patients, were subjected to the research. Mean age of patients were $48,67 \pm 11,67$, and mean foot number was 40,37 $\pm 2,78$. Daily walking length for patients ranged from 2 $\mathrm{km}$ to $10 \mathrm{~km}$, with a mean of 4,67 $\pm 2,12$. As expected and because of diabetic foot disease, patients had higher BMI levels. Comparison of foot pressure and other clinical parameters of patients were given in the Table 2. 
Table 2:- Arterial and some foot pressure level comparison of groups

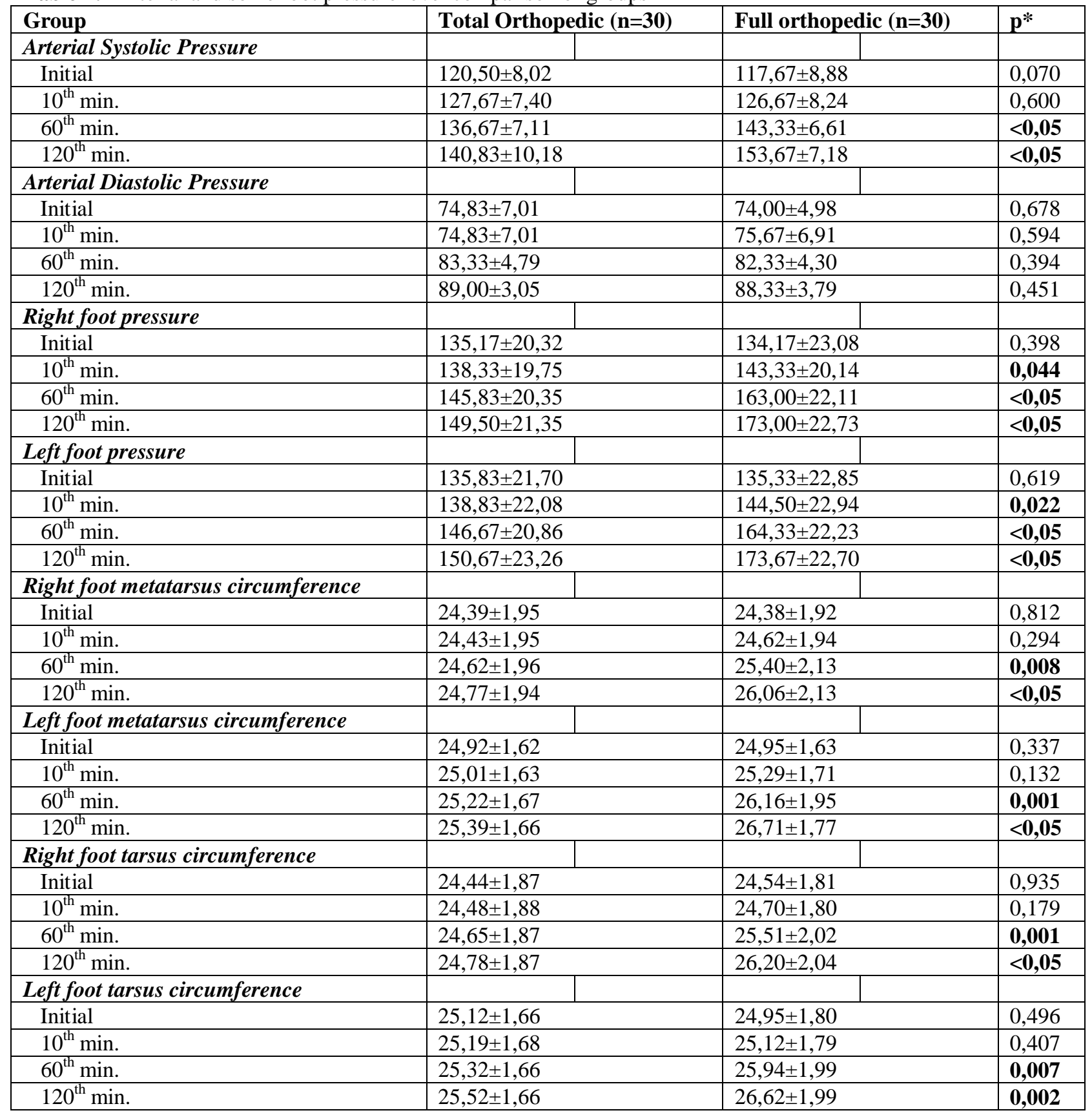

* Mann Whitney-U Test results.

As seen in the Table 2, newly designed footwear group results were lower, especially after 10th minutes. There were no statistically significant differences between groups for all pressure parameters at the initial $(p>0,05) .10$ minutes after wearing footwear, foot pressure differences for both right and left foot were statistically significant $(\mathrm{p}<0,05)$, while other parameter differences were insignificant $(p>0,05)$. 60 and 120 minutes after wearing footwear, all pressure parameters except arterial diastolic pressure showed statistically significant differences in high levels in the full orthopedic footwear $(\mathrm{p}<0,05)$. Perceived pain differences between groups were given in the Table 3 .

Table 3:- Perceived pain differences between groups

\begin{tabular}{|l|l|l|l|l|}
\hline Group & Total Orthopedic $(\mathrm{n}=30)$ & Full orthopedic $(\mathbf{n}=30)$ & $\mathbf{p}^{*}$ \\
\hline Perceived pain & & & & \\
\hline
\end{tabular}




\begin{tabular}{|l|l|l|l|}
\hline Initial & $1,07 \pm 0,25$ & $1,07 \pm 0,25$ & $>0,05$ \\
\hline $10^{\text {th }}$ min. & $1,23 \pm 0,43$ & $2,00 \pm 0,83$ & $<\mathbf{0 , 0 5}$ \\
\hline $60^{\text {th }}$ min. & $1,87 \pm 0,51$ & $3,53 \pm 0,68$ & $<\mathbf{0 , 0 5}$ \\
\hline $120^{\text {th }}$ min. & $2,30 \pm 0,70$ & $4,47 \pm 0,63$ & $<\mathbf{0 , 0 5}$ \\
\hline
\end{tabular}

* Mann Whitney-U Test results.

According to perceived pain results, initial pain level differences of groups were statistically insignificant ( $>0,05)$, whereas 10th, 60th, and 120th min. perceived pain differences were statistically and highly significant $(\mathrm{p}<0,05)$. Pressure change within time periods at different pressure points on foot is given in the Scheme 1.

Scheme 1:- Pressure change within time periods at different pressure points on foot
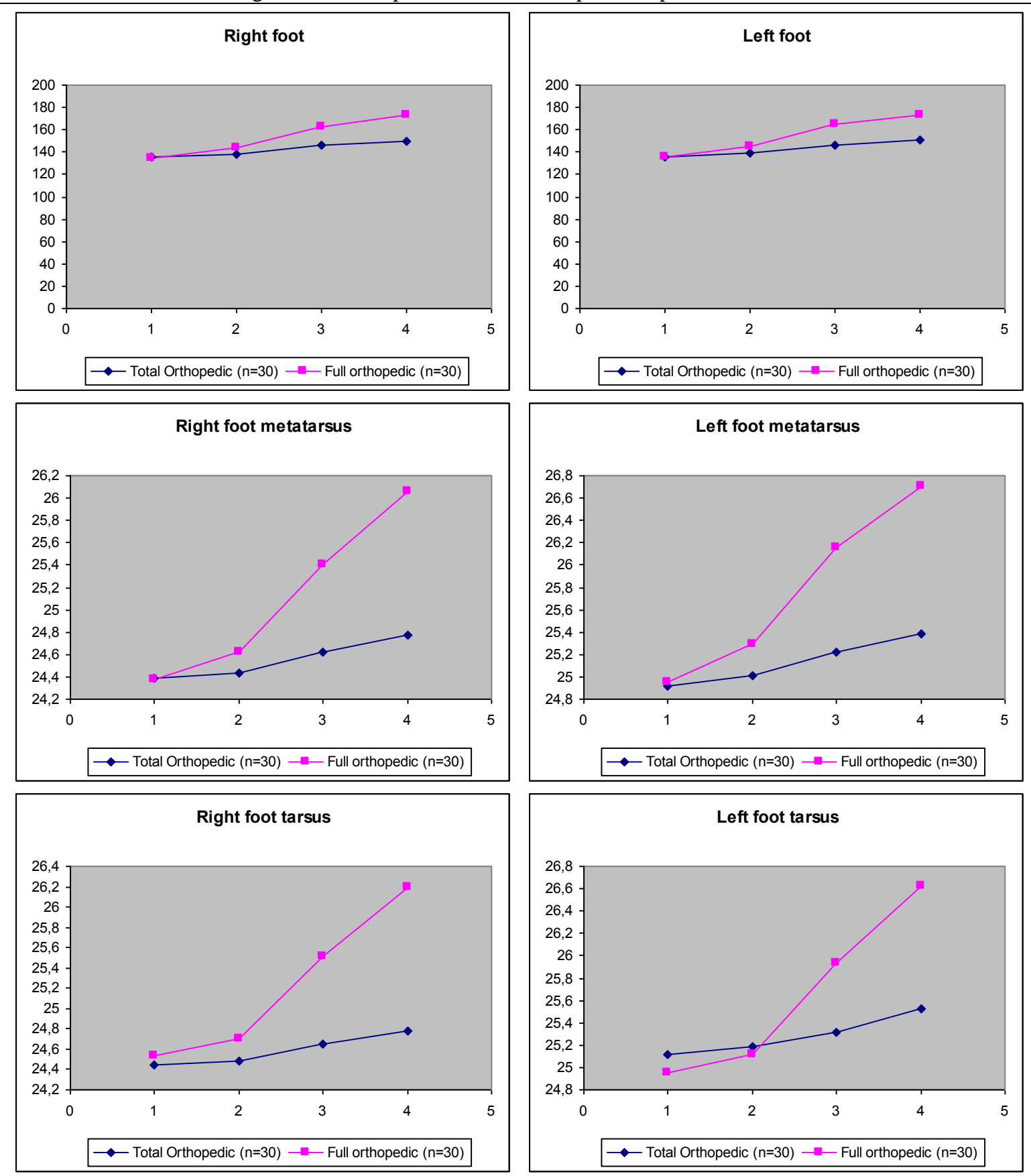
As seen Scheme 1, foot pressures for all points of the foot subjected in the research were in the increasing trend. Although total orthopedic footwear results were increasing in the time period, this increase was not as sharp as in the full orthopedic footwear results.

\section{Discussion:-}

DA (diabetic foot) is an important health and a life related problem with comorbid diseases. The incidence of the disease, especially with Type II DM, has become a real problem for public health, in the world (Besse et al., 2011). In addition, DA is concerned with the physical functions of individuals. In DA, the both neuropathic and peripheral artery complications of the DM is mainly suspected.

Some researchers have reported that plantar foot pressure is an important factor for DA (Pham and colleagues Art and Bus 2011, 2000; Frykberg et al., 1998). On the other hand, only plantar foot pressure or single-focussed shoes (Hafez, 2017) are not sufficient for the foot health. For this reason, other pressure points should be referred to in order to obtain better shoes.

Compared to orthopedic shoes, total orthopedic shoes, which is a OFCoF, arranges all pressure points on the foot. In addition to being covered with latex insoles found in all orthopedic shoes, by the presence of latex between the two leather forming all the enclosed areas. This allows total orthopedic shoes to flex from any direction, especially from the top. As a result, other pressure points outside the base are not exposed to traumatic pressure due to flexion. In particular, total orthopedic shoes, which have been used in practice, provide safer pressure results and lower neuropathic pain levels.

\section{Conclusion:-}

According to results; total orthopedic shoes reduce foot pressure, provide more comfortable and qualified foot stability. DA does not only affect the foot health of the patient, also affects the daily life of the individuals. In addition, it restricts the patient's daily walking exercises. High body weights and high body mass indexes in DM cause many more diseases associated with DM and obesity. Walking is a good exercise to combat high body mass index and obesity.

According to results; orthopedic shoes are not as comfortable as total orthopedic shoes. For this reason, it is recommended to use total orthopedic (Dia Comfort ${ }^{\circledR}$ ) shoes instead of orthopedic shoes in all DM, DA and health problems related to foot. It is also suggested that the work should be extended to include obesity patients, in addition to all DM and foot health problems.

\section{References:-}

1. Ahmad J. (2016). The diabetic foot. Diabetes \& Metabolic Syndrome: Clinical Research \& Reviews 10 (2016) 48-60.

2. Arts MLJ ve Bus SA. (2011). Twelve steps per foot are recommended for valid and reliable in-shoe plantar pressure data in neuropathic diabetic patients wearing custom made footwear. Clinical Biomechanics 26 (2011) 880-884.

3. Besse JL, Leemrijse T, Deleu PA. (2011). Diabetic foot: The orthopedic surgery angle. Orthopaedics \& Traumatology: Surgery \& Research (2011) 97, 314-329.

4. Bishop C, Hillier S, Thewlis D. (2017). The reliability of the Adelaide in-shoe foot model. Gait \& Posture 56 (2017) $1-7$.

5. Boulton AJM. (2014). The diabetic foot. Medicine, 4(3-1), 33-37.

6. Boulton AJ, Kirsner RS, Vileikyte L. (2004). Clinical practice. Neuropathic diabetic foot ulcers. N. Engl. J. Med. 351, 48-55.

7. Caravaggi P, Giangrande A, Lullini G, Padula G, Berti L, Leardini A. (2016). In shoe pressure measurements during different motor tasks while wearing safety shoes: The effect of custom made insoles vs. prefabricated and off-theshelf. Gait \& Posture 50 (2016) 232-238.

8. Chand G, Mishra AK, Kumar S, Agarwal A. (2012). Diabetic foot. Clinical Queries: Nephrology 0102 (2012) 144150 .

9. Gülman B.(2003). Diyabetik Ayak. Türk Ortopedi ve Traqvmatoloji Birliği Derneği Dergisi, 2 (1-2), 27-36.

10. Ito K, Maeda K, Fujiwara I, Hosoda K, Nagura T, Lee T ve Ogihara N. (2017). Dynamic measurement of surface strain distribution on the foot during walking. Journal of the mechanical behavior of biomedical materials 69 (2017) 249-256. 